\title{
Effects of Variable Production Rate and Time-Dependent Holding Cost for Complementary Products in Supply Chain Model
}

\author{
Mitali Sarkar, Sun Hur, and Biswajit Sarkar \\ Department of Industrial \& Management Engineering, Hanyang University, Ansan, Gyeonggi-do 155 88, Republic of Korea \\ Correspondence should be addressed to Biswajit Sarkar; bsbiswajitsarkar@gmail.com
}

Received 22 November 2016; Accepted 31 January 2017; Published 16 May 2017

Academic Editor: Gen Q. Xu

Copyright (C) 2017 Mitali Sarkar et al. This is an open access article distributed under the Creative Commons Attribution License, which permits unrestricted use, distribution, and reproduction in any medium, provided the original work is properly cited.

Recently, a major trend is going to redesign a production system by controlling or making variable the production rate within some fixed interval to maintain the optimal level. This strategy is more effective when the holding cost is time-dependent as it is interrelated with holding duration of products and rate of production. An effort is made to make a supply chain model (SCM) to show the joint effect of variable production rate and time-varying holding cost for specific type of complementary products, where those products are made by two different manufacturers and a common retailer makes them bundle and sells bundles to end customers. Demand of each product is specified by stochastic reservation prices with a known potential market size. Those players of the SCM are considered with unequal power. Stackelberg game approach is employed to obtain global optimum solution of the model. An illustrative numerical example, graphical representation, and managerial insights are given to illustrate the model. Results prove that variable production rate and time-dependent holding cost save more than existing literature.

\section{Literature Review}

Nowadays, supply chain management is the key area of research in each field of business sector (see for reference Sarkar [1]). The most crucial factor in supply chain is to obtain more profit or to reduce a total system cost. To earn more profit, selling-price plays an important role as less sellingprice with perfect quality product will give always increasing market size of any product. Thus, if any industry can maintain an optimum selling-price for a long period of time, the industry may consider a sustainable supply chain forever with known market size.

Therefore, based on the optimum selling-price there are two options for market size: if selling-price is in the optimum level then anyone can conclude that the supply chain is moving with known market size without shortages; otherwise it can be assumed that the market size of the supply chain continues with random market size, where shortage can appear any time. Therefore, it can be concluded that, with the optimum selling-price, known market sizes, and production greater than demand always, any industry can assume a sustainable supply chain system without any shortage of any product at anytime (see for reference Sarkar and Lee [2], Cárdenas-Barrón and Sana [3], and Modak et al. [4]).

Though there are several researches about the optimized selling-price within the supply chain framework, only few models were considered the optimized selling-price for complementary products. By definition, complementary product means these products which cannot be used without help of another like stapler and its pin and bed and mattress. These complementary types of products are generally very basic products for our daily use purpose and prices of these products are very low compared to other products. The case of substitutable products has been widely studied in literature for a long time. This is the basic traditional competition for substitutable products, where customers choose products by their performance or marketing strategies of the industries. But as on Yue et al. [5] model, the concept of complementary products arises when customers have to buy more than one product at the same time to obtain full utility of both products. Recently, these complementary products are gaining interest in research as it is found that several complementary 
TABLE 1: Author's contribution.

\begin{tabular}{|c|c|c|c|c|c|c|}
\hline Author (s) & SCM & Variable production rate & Reservation price & Variable holding cost & Game approach & Stochastic demand \\
\hline Wei et al. [14] & $\sqrt{ }$ & & & & $\sqrt{ }$ & \\
\hline Sarkar and Lee [2] & $\sqrt{ }$ & & $\sqrt{ }$ & & $\sqrt{ }$ & $\sqrt{ }$ \\
\hline Alfares and Ghaithan [9] & & $\sqrt{ }$ & & & & \\
\hline Sarkar et al. [12] & & $\sqrt{ }$ & & $\sqrt{ }$ & & \\
\hline This model & $\sqrt{ }$ & $\sqrt{ }$ & $\sqrt{ }$ & $\sqrt{ }$ & $\sqrt{ }$ & $\sqrt{ }$ \\
\hline
\end{tabular}

products are used in our daily life as toothpaste and toothbrush. The best examples for complementary products are computer and its operating system, computer hardware and software, and digital versatile disk (DVD) player and DVD. In this direction, Choi [6] introduced complementary products within the supply chain management.

Gabszewicz et al. [7] introduced price competition for a firm, which produces complementary products always giving more profit in coordination policy than the noncoordination policy between the player of the firm. McCardle et al. [8] introduced that bundling these complementary products will give more perfect result than the single selling within a basic inventory model. They did not prove the effect of bundling policy for complementary product within the supply chain network, though they introduced reservation price within the literature of basic inventory model. Based on these studies till now, an immediate research gap can be found as what will be the feature of bundling for complimentary products within the framework of supply chain where the reservation price is already utilized? This research gap is fulfilled by Sarkar and Lee [2] and they proved that for bundling policy holding cost and production rate of both manufacturers, who produce complementary products, play some important roles within the supply chain. Alfares and Ghaithan [9] proved that timedependent holding cost always plays an important role and Sarkar et al. [10] developed effect of variable production rate, which is close to Manna and Chaudhuri [11]. Sarkar et al. [12] discussed the effect of time-dependent holding cost in the basic inventory model. Therefore, the immediate research gap arises: what will be the feature of supply chain model with time-dependent holding cost and demand-dependent production rate for both the manufacturers and who would like to produce basic complementary products? This research gap is fulfilled by the proposed model along with the cooperation and noncooperation policy within the supply chain players that are employed as nowadays many supply chain players are with unequal powers. Therefore, Stackelberg game policy is employed to solve the model, which is suggested by many researchers in this field of research with leaderfollowers strategies (see for reference Mukhopadhyay et al. [13] and Wei et al. [14])

This model is on the basic products only whereas for the larger products the same model can be applied without any change. The airline industries recently plan for the chip air tickets and the tour plans for each country. That can be used as a complementary products like (i) trip tickets and (ii) tour package. The second example of large complementary products is (i) trip airlines tickets and (ii) hotel booking for the same city. Recently, many airlines industries are using the concept of complementary products for their tickets and hotels for the same cities as a compact package with some attractive prices for which this model can be directly used without any change. This present study considers a two-echelon supply chain model with two duopolistic manufacturers and a common retailer. The manufacturers produce two types of complementary products. The retailer purchases complementary products using reservation price and makes bundles with complementary products and sells those bundles of complementary products to customers. The production rate for each of the manufacturer is demanddependent and holding cost is time-dependent. Due to unequal power of SCM players, Stackelberg game approach with noncooperation strategies and cooperation strategy are employed to obtain global optimum solution of the model. Several managerial insights are discussed based on their profits and analytical derivations. The rest of the paper is designed as follows: problem definition, notation, and assumptions are given in Section 2. The mathematical model is described in Section 3. Numerical example, graphical representations, and sensitivity analysis are illustrated in Section 4. Finally conclusions and future extensions are given in Section 5. Please refer to Table 1 for the contribution of different authors in the field of this study.

\section{Problem Definition, Notation, and Assumptions}

This section considers problem definition, notation, and assumptions.

2.1. Problem Definition. A two-echelon supply chain is considered with two manufacturers and a common retailer for complementary products. Retailer sells bundles of complementary products, which contain product 1 (made by manufacturer 1) and product 2 (made by manufacturer 2 ). When the retailer places an order quantity $Q$ of some complementary products (as product 1 and product 2) to manufacturers (manufacturer 1 and manufacturer 2), anyone within these manufacturers (we assume manufacturer 2) responds first with any type of products (product 1 if manufacturer 1 and product 2 if manufacturer 2) with $Q$ quantity and another manufacturer (we assume 1st manufacturer) has to make the same $Q$ quantity of other parts of complementary products. As one manufacturer responds 1st and another manufacturer has to follow both of them (common retailer and the manufacturer who responds first), thus the leaderfollower strategy is used to obtain the optimum profit of the supply chain. Within two leaders, one may sometimes think 
about his own profit, he may not think about the whole supply chain profit, or it may happen that both leaders may think about their total supply chain profit. Based on this strategy, the noncooperation and cooperation strategy are considered. The production rates of both manufacturers are dependent on demand of that manufacturer and demand is dependent on selling-price, which is based on stochastic reservation price. The holding cost for each manufacturer is considered as time-dependent. The aim is to maximize the profit of the supply chain to analyze the effect of variable production rate and time-dependent holding cost for specific type as complementary products, where the player of supply chain is with unequal profit.

2.2. Notation. The following notation is used to develop this proposed model.

Decision Variables

Q: lot size

$P_{i}$ : selling-price of product $i, i=1,2$

$P_{r}$ : selling-price of bundle product

\section{Parameters}

$T_{m_{i}}$ : cycle length of manufacturer $i, i=1,2$

$T_{r}$ : cycle length of the common retailer

$t_{m_{i}}$ : maximum inventory for holding time product $i$, $i=1,2$

$\mu_{m_{i}}$ : constant multiplier of demand rate of product $i$ to obtain the production rate, $i=1,2$

$p_{m_{i}}$ : production rate of manufacturer $i=\mu_{m_{i}} D_{m_{i}}, i=$ 1,2

$S_{m_{i}}:$ setup cost per setup of product $i, i=1,2$

$C_{i}$ : purchasing cost of product $i, i=1,2$

$M$ : known market size

$D_{m_{i}}:$ demand of product $i, i=1,2$

$D_{r}$ : demand of bundle product

$h_{m_{i}}$ : holding cost of product $i$ per unit per unit time $=$ $h_{m_{i j}}+t h_{m_{i j}}, i, j=1,2, i \neq j$

$h_{r}$ : holding cost of bundle product per unit per unit time

$I_{m_{i 1}}$ : inventory of manufacturer $i$ at time $t$ during $\left[0, t_{m i}\right]$

$I_{m_{i 2}}$ : inventory of manufacturer $i$ at time $t$ during $\left[t_{m i}, T_{m i}\right]$

$I_{r}$ : inventory of retailer at time $t$ during $\left[0, T_{r}\right]$

$A$ : ordering cost per order of the retailer

$R_{i}^{a}$ : lower limit of reservation price of product $i, i=$ 1,2

$R_{i}^{b}$ : upper limit of reservation price of product $i, i=$ 1,2
$\mathrm{AP}_{m_{i}}$ : expected average profit of manufacturer $i, i=$ 1,2

$\mathrm{AP}_{r}$ : expected average profit of retailer.

2.3. Assumptions. The following assumptions are considered to develop the model.

(1) In this model, a two-echelon supply chain model is considered with two manufacturers and one common retailer. Two manufacturers make two types of separate (but complementary) products and the common retailer makes them bundle and sells them.

(2) Demand for retailer is assumed for bundle products as stochastic in nature; that is, $D_{r}=\left(P_{r}-P_{1}-\right.$ $\left.P_{2}\right)\left(M\left(2-2 P_{r}+R_{2}^{a}+R_{2}^{b}\right) / 2\right)$ and the demand of the duopolistic manufacturers is also stochastic in nature; that is, $D_{m_{1}}=M\left(1-P_{1}\right)$ and $D_{m_{2}}=M\left(\left(R_{2}^{b}-P_{2}\right) /\left(R_{2}^{b}-\right.\right.$ $\left.R_{2}^{a}\right)$ ). Along with the stochastic nature of demand, the demands are dependent on reservation price (see for reference Sarkar and Lee [2]). The production rates of both manufacturers are dependent on demand rate; that is, $p_{m_{1}}=\mu_{m_{1}} D_{m_{1}}$ and $p_{m_{2}}=\mu_{m_{2}} D_{m_{2}}$ (see for reference Manna and Chaudhuri [11]).

(3) Since, in the basic inventory model, the holding cost is considered as constant, even though, based on the time, the holding cost is increased for most of the complementary products when departure date of any airline flight is coming closer, then the airline updates the increasing price of air tickets along the value of the tour-packages. For the basic products, if those products are holding for a long time in a shopping mall, the holding cost of those products must increase with the increasing value of time. It is assumed that the holding costs are time-dependent; that is, $h_{m_{1}}=h_{m_{11}}+t h_{m_{12}}$ and $h_{m_{2}}=h_{m_{21}}+t h_{m_{22}}$ for both manufacturers, whereas the holding cost for common retailer is considered as constant.

(4) This model assumes if retailer places an order, any (it is assumed second) manufacturer responds first; then manufacturer along with retailer becomes leader and another manufacturer becomes follower.

(5) Stackelberg game policy is employed to solve the model as there is an asymmetry in power (see for reference Sarkar and Lee [2]).

(6) There are no shortages for the retailer and two manufacturers even though the production rate is variable, but it should be within certain limit such that demand never exceeds.

(7) There is no information asymmetry in this model.

\section{Model Formulation}

Two manufacturers produce two basic complementary types of products as product 1 and product 2 . It is assumed that, without any loss of generality, upper limit of reservation price of manufacturer 1 is 1 and lower limit is 0 as those 
are very basic products with less price than other products. Manufacturers buy raw materials at $C_{1}$ and $C_{2}$ and sell them to the retailer at $P_{1}$ and $P_{2}$. The demand of each product 1 and product 2 is specified by the reservation price $R_{1}$ and $R_{2}$, respectively. The model assumes that there is a potential market for complementary products with known market size $M$. The assumption of market size $M$ is reasonable as products are basic products and there are old available past data. However, uncertainty occurs due to the variability in reservation prices. The distribution of reservation prices for product 1 and product 2 is assumed to be uniform between $R_{1}^{a}$ and $R_{1}^{b}$ for product 1 and $R_{2}^{a}$ and $R_{2}^{b}$ for product 2 . The model assumes without any loss of generality that $R_{1}^{a}=0$ and $R_{1}^{b}=$ 1. Thus, it can be obtained that $R_{2}^{a} \geq 0, C_{1} \leq 1$, and $C_{2} \leq R_{2}^{b}$. Finally, the model assumes $R_{2}^{b} \leq 1$.

The demand of product 1 from manufacturer 1 is given by $D_{m_{1}}=M\left(1-P_{1}\right)$

$$
D_{m_{1}}=M \int_{P_{1}}^{1} \frac{1}{1-0} d x_{1}=M\left(1-P_{1}\right) .
$$

The demand of product 2 from manufacturer 2 is based on reservation price as

$$
D_{m_{2}}=M \int_{P_{2}}^{R_{2}^{b}} \frac{1}{R_{2}^{b}-R_{2}^{a}} d x_{1}=M\left(\frac{R_{2}^{b}-P_{2}}{R_{2}^{b}-R_{2}^{a}}\right) .
$$

3.1. Profit of Manufacturer 1. The production process of product 1 is started at time $t=0$ with the demand-dependent production rate $p_{m_{1}}=\mu_{m_{1}} D_{m_{1}}$ to produce a lot $Q$ and it continues until $t_{m_{1}}=Q / p_{m_{1}}=Q / \mu_{m_{1}} D_{m_{1}}$. The inventory depletes due to demand $D_{m_{1}}$ to zero at $t=T$ (see Figure 1 ).

The governing differential equations of manufacturer 1 are given by

$$
\begin{aligned}
& \frac{d I_{m_{11}}(t)}{d t}=p_{m_{1}}-D_{m_{1}}=\left(\mu_{m_{1}}-1\right) D_{m_{1}}, \\
& \quad 0 \leq t \leq t_{m_{1}}, I_{m_{11}}(0)=0 \\
& \frac{d I_{m_{12}}(t)}{d t}=-D_{m_{1}}, \quad t_{m_{1}} \leq t \leq T_{m_{1}}, I_{m_{12}}\left(T_{m_{1}}\right)=0 .
\end{aligned}
$$

Solutions of the above equations give the inventory positions of manufacturer 1 at time $t$; that is,

$$
\begin{aligned}
& I_{m_{11}}(t)=\left(\mu_{m_{1}}-1\right) D_{m_{1}} t, \quad 0 \leq t \leq t_{m_{1}} \\
& I_{m_{12}}(t)=D_{m_{1}}\left(T_{m_{1}}-1\right), \quad t_{m_{1}} \leq t \leq T_{m_{1}} .
\end{aligned}
$$

As at $t_{m}$, both the inventory positions are continuous, thus, equating the above two equation at the time $t_{m_{1}}$, one can obtain

$$
t_{m_{1}}=\frac{Q}{\mu_{m_{1}} D_{m_{1}}} .
$$

To calculate the profit of manufacture 1 , one has to calculate all manufacturer l's different cost expression. Therefore, the following costs are calculated as follows.

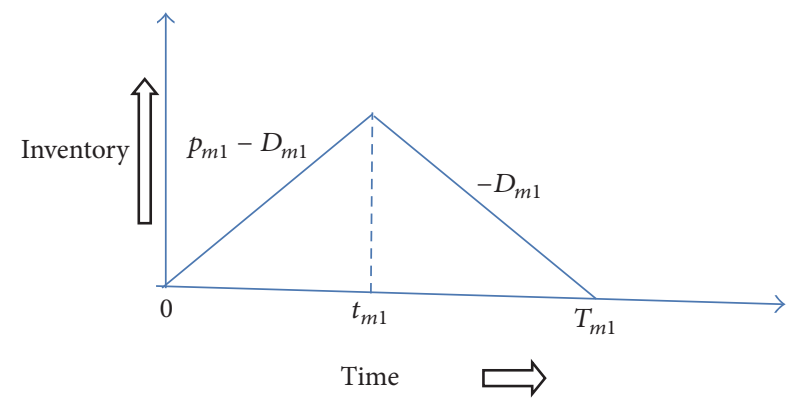

FIGURE 1: Inventory position of manufacturer 1.

Setup Cost $\left(S_{1}\right)$. Manufacturer 1 produces product 1 . Thus, the basic setup has to invest for product 1 . Therefore, the setup cost for manufacturer 1 is

$$
\mathrm{SC}_{1}=\frac{S_{m_{1}} D_{m_{1}}}{Q}
$$

Holding Cost $\left(\mathrm{HC}_{1}\right)$. As production rate is not fixed, it is assumed as demand-dependent and demand is variable; therefore anytime shortages can occur. Thus to prevent the shortages, the time-varying holding cost is considered to control the shortages. A linear time-dependent holding cost pattern (see reference Alfares \& Ghaithan [9]) is considered and the holding cost for manufacturer 1 is given by

$$
\begin{aligned}
\mathrm{HC}_{1}= & h_{m_{11}} \int_{0}^{t_{m_{1}}} I_{m_{11}}(t) d t+h_{m_{12}} \int_{t_{m_{1}}}^{T_{m 1}} t I_{m_{12}}(t) d t \\
= & \frac{h_{m_{11}} Q^{2}}{2 D_{m_{1}} \mu_{m_{1}}}\left(1-\frac{1}{\mu_{m_{1}}}\right) \\
& +\frac{h_{m_{12}} Q^{3}}{6 D_{m_{1}}^{2}}\left(1+\frac{1}{6 \mu_{m_{1}}^{3}}-\frac{3}{\mu_{m_{1}}^{2}}\right) .
\end{aligned}
$$

The revenue for manufacturer 1 is $=\left(P_{1}-C_{1}\right) D_{m_{1}}$.

Thus, the average profit for manufacturer 1 is

$$
\begin{aligned}
\operatorname{AP}_{m_{1}}\left(P_{1}, Q\right)= & \left(P_{1}-C_{1}\right) D_{m_{1}}-\frac{S_{m_{1}} D_{m_{1}}}{Q} \\
& -\frac{h_{m_{11}} Q^{2}}{2 D_{m_{1}} \mu_{m_{1}}}\left(1-\frac{1}{\mu_{m_{1}}}\right) \\
& -\frac{h_{m_{12}} Q^{3}}{6 D_{m_{1}}^{2}}\left(1+\frac{1}{6 \mu_{m_{1}}^{3}}-\frac{3}{\mu_{m_{1}}^{2}}\right) .
\end{aligned}
$$

To calculate the profit of the supply chain, the profit of manufacturer 2 has to be calculated. Thus, in next subsection, the profit of manufacturer 2 can be calculated.

3.2. Profit for Manufacturer 2. Similar as manufacturer 1, the production process of product 2 is started at time $t=0$ with the demand-dependent production rate $p_{m_{2}}=\mu_{m_{2}} D_{m_{2}}$ 


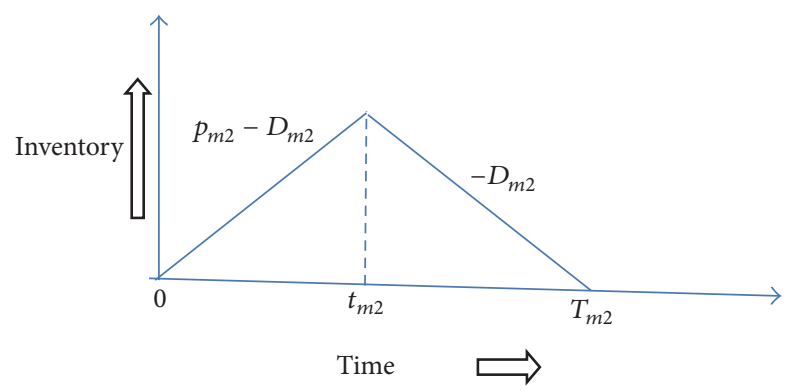

FIGURE 2: Inventory position of manufacturer 2.

to produce a lot $Q$ and it continues until $t_{m_{2}}=Q / p_{m_{2}}=$ $Q / \mu_{m_{2}} D_{m_{2}}$. The inventory depletes due to demand $D_{m_{2}}$ to zero at $t=T_{m_{2}}$ (see Figure 2).

The governing differential equations of manufacturer 2 are given by

$$
\begin{aligned}
& \frac{d I_{m_{21}}(t)}{d t}=p_{m_{2}}-D_{m_{2}}=\left(\mu_{m_{2}}-1\right) D_{m_{2}}, \\
& \quad 0 \leq t \leq t_{m_{2}}, I_{m_{21}}(0)=0 \\
& \frac{d I_{m_{22}}(t)}{d t}=-D_{m_{2}}, \quad t_{m_{2}} \leq t \leq T_{m_{2}}, I_{m_{22}}\left(T_{m_{2}}\right)=0 .
\end{aligned}
$$

Solutions of the above equations to obtain the present inventory positions at time $t$ for manufacturer 2 are given by

$$
\begin{aligned}
& I_{m_{21}}(t)=\left(\mu_{m_{2}}-1\right) D_{m_{2}} t, \quad 0 \leq t \leq t_{m_{2}} \\
& I_{m_{22}}(t)=D_{m_{2}}\left(T_{m_{2}}-1\right), \quad t_{m_{2}} \leq t \leq T_{m_{2}} .
\end{aligned}
$$

From the continuity condition, equating the above two equations at the time $t_{m_{2}}$, it can be obtained that

$$
t_{m_{2}}=\frac{Q}{\mu_{m_{2}} D_{m_{2}}} .
$$

Setup Cost $\left(\mathrm{SC}_{2}\right)$. Similar as manufacturer 1, the setup cost for manufacturer 2 is

$$
\mathrm{SC}_{2}=\frac{S_{m_{2}} D_{m_{2}}}{Q}
$$

Holding Cost $\left(\mathrm{HC}_{2}\right)$. For holding cost also, similar as manufacturer 1 , the holding cost for manufacturer 2 is given by

$$
\begin{aligned}
\mathrm{HC}_{2}= & h_{m_{21}} \int_{0}^{t_{m_{2}}} I_{m_{21}}(t) d t+h_{m_{22}} \int_{t_{m_{2}}}^{T_{m_{2}}} t I_{m_{22}}(t) d t \\
= & \frac{h_{m_{21}} Q^{2}}{2 D_{m_{2}} \mu_{m_{2}}}\left(1-\frac{1}{\mu_{m_{2}}}\right) \\
& +\frac{h_{m_{22}} Q^{3}}{6 D_{m_{2}}^{2}}\left(1+\frac{1}{6 \mu_{m_{2}}^{3}}-\frac{3}{\mu_{m_{2}}^{2}}\right) .
\end{aligned}
$$

The revenue for manufacturer 2 is $=\left(P_{2}-C_{2}\right) D_{m_{2}}$.

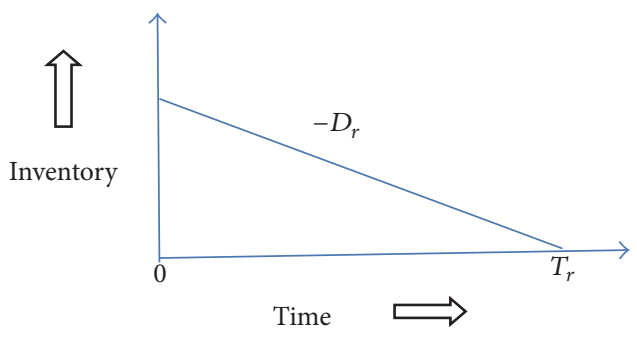

FIgURE 3: Inventory position of the common retailer.

Thus, the average profit for manufacturer 2 is

$$
\begin{aligned}
\operatorname{AP}_{m_{2}}\left(P_{2}, Q\right)= & \left(P_{2}-C_{2}\right) D_{m_{2}}-\frac{S_{m_{2}} D_{m_{2}}}{Q} \\
& -\frac{h_{m_{21}} Q^{2}}{2 D_{m_{2}} \mu_{m_{2}}}\left(1-\frac{1}{\mu_{m_{2}}}\right) \\
& -\frac{h_{m_{22}} Q^{3}}{6 D_{m_{2}}^{2}}\left(1+\frac{1}{6 \mu_{m_{2}}^{3}}-\frac{3}{\mu_{m_{2}}^{2}}\right) .
\end{aligned}
$$

After making product 1 by manufacturer 1 and product 2 by manufacturer 2, they sell to their common retailer. Therefore, the profit of retailer has to calculate to obtain the profit of the supply chain.

3.3. Profit for the Common Retailer. Due to making bundles of product 1 and product 2 , the demand $\left(D_{r}\right)$ pattern changes for the case of retailer. Therefore, the demand, by considering stochastic reservation price, of retailer is as follows:

$$
\begin{aligned}
D_{r} & =M \int_{\max \left\{P_{r-1}, R_{2}^{a}\right\}}^{R_{2}^{b}}\left(\int_{\max \left\{P_{r}-x_{2}, 0\right\}}^{1} d x_{1}\right) \frac{1}{R_{2}^{b}-R_{2}^{a}} d x_{2} \\
& =M\left(\frac{2-2 P_{r}+R_{2}^{b}+R_{2}^{a}}{2}\right) .
\end{aligned}
$$

The governing differential equations of the common (see Figure 3) retailer are

$$
\frac{d I_{r}(t)}{d t}=-D_{r}, \quad 0 \leq t \leq T_{r}, I_{r}(0)=Q .
$$

To calculate the profit of the retailer, the following costs have to be calculated.

Ordering Cost $\left(\mathrm{OC}_{r}\right)$. The ordering cost for the common retailer is

$$
\mathrm{OC}_{r}=\frac{A M\left(2-2 P_{r}+R_{2}^{b}+R_{2}^{a}\right)}{2 \mathrm{Q}} .
$$

Holding Cost $\left(\mathrm{HC}_{r}\right)$. The holding cost for the common retailer is

$$
\mathrm{HC}_{r}=\frac{h_{r} \mathrm{Q}}{2} .
$$

The revenue for the common retailer is $=\left(P_{r}-P_{1}-P_{2}\right) D_{r}$. 
The profit for the retailer is

$$
\begin{aligned}
\mathrm{AP}_{r}= & \left(P_{r}-P_{1}-P_{2}\right)\left(\frac{M\left(2-2 P_{r}+R_{2}^{b}+R_{2}^{a}\right)}{2}\right) \\
& -\left(\frac{A M\left(2-2 P_{r}+R_{2}^{b}+R_{2}^{a}\right)}{2 Q}\right)-\frac{h_{r} Q}{2} .
\end{aligned}
$$

The model assumes when the retailer places an order, manufacturer 2 accepts the order first. Based on the joint discussion of the retailer and manufacturer 2, manufacturer 1 has to follow the same amount, which manufacturer 2 offers to the retailer. It means that all players are not with same power. Thus, the total cost of manufacturers and retailer cannot be added directly as it may be considered in the basic supply chain model. To solve this leader-follower problem, Stackelberg game approach is the best procedure; thus, it is used to solve the model. Thus for this model, manufacturer 2 and retailer act as the leader and manufacturer 1 acts as the follower. But based on cooperation and noncooperation policy between the leaders, there are two cases as Case 1: noncooperation between leaders (manufacturer 2 and common retailer) and follower (manufacturer 1 ) and Case 2: cooperation between leaders (manufacturer 2 and common retailer) and follower (manufacturer 1). In next Section, the solution methodology, based on Stackelberg policy, is discussed.

\subsection{Solution Methodology}

Case 1 (noncooperation between leaders (manufacturer 2 and common retailer) and follower (manufacturer 1)). To solve the model, Stackelberg game policy is used here. The following lemma is constructed to obtain the global maximum profit of the player of supply chain.

Theorem 1. $Q^{*}$ and $P_{1}^{*}$ are the global optimum lot size and selling-price, respectively, of manufacturer 1 if the following are satisfied:

(1)

$$
\begin{aligned}
\xi_{1} Q^{* 4}+\xi_{2} Q^{* 3}-\xi_{3}=0, & P_{1}^{*}=\frac{1}{2}\left[C_{1}+1+\frac{S_{m_{1}}}{Q}-\frac{h_{m_{11}} Q^{* 2}\left(1-1 / \mu_{m_{1}}\right)}{M^{2} \mu_{m_{1}}\left(1-P_{1}^{*}\right)^{2}}\right. \\
& \left.-\frac{h_{m_{12}} Q^{* 3}\left(1+1 / 6 \mu_{m_{2}}^{3}-3 / \mu_{m_{2}}^{2}\right)}{3 M^{3} \mu_{m_{1}}\left(1-P_{1}^{*}\right)^{3}}\right]
\end{aligned}
$$

(2)

$$
\begin{aligned}
& {\left[\frac{2 \xi_{3}}{Q^{* 3}}+\xi_{2}+2 \xi_{1} Q\right]>0} \\
& \text { or, }\left[2 M+2 \frac{h_{m_{11}} Q^{* 2}\left(1-1 / \mu_{m_{1}}\right)}{M \mu_{m_{1}}\left(1-P_{1}^{*}\right)^{3}}\right.
\end{aligned}
$$

$$
\begin{aligned}
& \left.+\frac{h_{m_{12}} Q^{* 3}\left(1+1 / 6 \mu_{m_{2}}^{3}-3 / \mu_{m_{2}}^{2}\right)}{M^{2} \mu_{m_{1}}\left(1-P_{1}^{*}\right)^{4}}\right]>0 \\
& {\left[\frac{2 \xi_{3}}{Q^{* 3}}+\xi_{2}+2 \xi_{1} Q\right]\left[2 M+2 \frac{h_{m_{11}} Q^{* 2}\left(1-1 / \mu_{m_{1}}\right)}{M \mu_{m_{1}}\left(1-P_{1}^{*}\right)^{3}}\right.} \\
& \left.+\frac{h_{m_{12}} Q^{* 3}\left(1+1 / 6 \mu_{m_{2}}^{3}-3 / \mu_{m_{2}}^{2}\right)}{M^{2} \mu_{m_{1}}\left(1-P_{1}^{*}\right)^{4}}\right]-\left[\frac{M S_{m_{1}}}{Q^{* 2}}\right. \\
& \left.+2 \frac{h_{m_{11}} Q^{* 2}\left(1-1 / \mu_{m_{1}}\right)}{M \mu_{m_{1}}\left(1-P_{1}^{*}\right)^{3}}\right]^{2}>0 . \\
& \left.+\frac{h_{m_{12}} Q^{* 3}\left(1+1 / 6 \mu_{m_{2}}^{3}-3 / \mu_{m_{2}}^{2}\right)}{M^{2} \mu_{m_{1}}\left(1-P_{1}^{*}\right)^{4}}\right]^{2}
\end{aligned}
$$

Proof. Taking derivative two times of the profit equation of manufacturer 1 with respect to $Q$, one can obtain

$$
\begin{aligned}
\frac{\partial \mathrm{AP}_{m_{1}}}{\partial \mathrm{Q}} & =-\xi_{1} \mathrm{Q}^{2}-\xi_{2} \mathrm{Q}+\frac{\xi_{3}}{\mathrm{Q}^{2}}, \\
\frac{\partial^{2} \mathrm{AP} m_{1}}{\partial Q^{2}} & =-\left[\frac{2 \xi_{3}}{Q^{3}}+\xi_{2}+2 \xi_{1} \mathrm{Q}\right]<0 .
\end{aligned}
$$

By using necessary condition of optimization, it gives

$$
\begin{array}{r}
\frac{\partial \mathrm{AP}_{m_{1}}}{\partial Q}=0 \\
\text { i.e., } \xi_{1}\left(Q^{*}\right)^{4}+\xi_{2}\left(Q^{*}\right)^{3}-\xi_{3}=0,
\end{array}
$$

where

$$
\begin{aligned}
& \xi_{1}=\frac{h_{m_{12}}\left(1+1 / 6 \mu_{m_{2}}^{3}-3 / \mu_{m_{2}}^{2}\right)}{2 D_{m_{1}}^{2}}, \\
& \xi_{2}=\frac{h_{m_{11}}\left(1-1 / \mu_{m_{1}}\right)}{D_{m_{1}} \mu_{m_{1}}}, \\
& \xi_{3}=S_{m_{1}} D_{m_{1}} .
\end{aligned}
$$

Taking derivative with respect to $P_{1}$ two times of the profit equation of manufacturer 1 and equating to zero as well as using the optimum $Q^{*}$, it can be found as

$$
\begin{gathered}
P_{1}^{*}=\frac{1}{2}\left[C_{1}+1+\frac{S_{m_{1}}}{Q^{*}}-\frac{h_{m_{11}} Q^{* 2}\left(1-1 / \mu_{m_{1}}\right)}{M^{2} \mu_{m_{1}}\left(1-P_{1}^{*}\right)^{2}}\right. \\
\left.-\frac{h_{m_{12}} Q^{* 3}\left(1+1 / 6 \mu_{m_{2}}^{3}-3 / \mu_{m_{2}}^{2}\right)}{3 M^{3} \mu_{m_{1}}\left(1-P_{1}^{*}\right)^{3}}\right], \\
\frac{\partial^{2} \mathrm{AP}_{m_{1}}}{\partial P_{1}^{2}}=-\left[2 M+2 \frac{h_{m_{11}} Q^{* 2}\left(1-1 / \mu_{m_{1}}\right)}{M \mu_{m_{1}}\left(1-P_{1}^{*}\right)^{3}}\right. \\
\left.+\frac{h_{m_{12}} Q^{* 3}\left(1+1 / 6 \mu_{m_{2}}^{3}-3 / \mu_{m_{2}}^{2}\right)}{M^{2} \mu_{m_{1}}\left(1-P_{1}^{*}\right)^{4}}\right]<0 .
\end{gathered}
$$


1st conditions of Theorem 1 are satisfied. Now, we check the 2nd condition.

The above equation must be satisfied by the optimal selling-price $P_{1}$ of product 1 .

Finally, in the expression for the second principal minor, the 1st term is too big compared to second term. Thus, it is greater than zero.

$$
\begin{gathered}
\frac{\partial^{2} \mathrm{AP}_{m_{1}}}{\partial Q^{2}} \frac{\partial^{2} \mathrm{AP}_{m_{1}}}{\partial P_{1}^{2}}-\left(\frac{\partial^{2} \mathrm{AP}_{m_{1}}}{\partial Q \partial P_{1}}\right)^{2}=\left[\frac{2 \xi_{3}}{\mathrm{Q}^{* 3}}+\xi_{2}\right. \\
\left.+2 \xi_{1} Q^{*}\right]\left[2 M+2 \frac{h_{m_{11}} \mathrm{Q}^{* 2}\left(1-1 / \mu_{m_{1}}\right)}{M \mu_{m_{1}}\left(1-P_{1}^{*}\right)^{3}}\right. \\
\left.+\frac{h_{m_{12}} \mathrm{Q}^{* 3}\left(1+1 / 6 \mu_{m_{2}}^{3}-3 / \mu_{m_{2}}^{2}\right)}{M^{2} \mu_{m_{1}}\left(1-P_{1}^{*}\right)^{4}}\right]-\left[\frac{M S_{m_{1}}}{Q^{* 2}}\right. \\
\left.+2 \frac{h_{m_{11}} Q^{* 2}\left(1-1 / \mu_{m_{1}}\right)}{M \mu_{m_{1}}\left(1-P_{1}^{*}\right)^{3}}\right]^{2}>0 . \\
\left.+\frac{h_{m_{12}} Q^{* 3}\left(1+1 / 6 \mu_{m_{2}}^{3}-3 / \mu_{m_{2}}^{2}\right)}{M^{2} \mu_{m_{1}}\left(1-P_{1}^{*}\right)^{4}}\right]^{2}
\end{gathered}
$$

From the sufficient condition, principal minors are alternating in sign. Thus, the optimal solution is the global maximum. Hence, this completes the proof.

Theorem 2. Using the optimum lot size $Q^{*}$, the profit of manufacturer 2 has the global maximum price at $P_{2}^{*}$, if $P_{2}^{*}$ satisfies

$$
\begin{gathered}
{\left[\frac{2 M P_{2}^{*}}{R_{2}^{b}-R_{2}^{a}}+\frac{\left(R_{2}^{b}-R_{2}^{a}\right) h_{m_{21}} Q^{* 2}\left(1-1 / \mu_{m_{2}}\right)}{2 M \mu_{m_{2}}\left(R_{2}^{b}-P_{2}^{*}\right)^{2}}\right.} \\
\left.+\frac{h_{m_{22}} Q^{* 3}\left(R_{2}^{b}-R_{2}^{a}\right)^{2}\left(1+1 / 6 \mu_{m_{2}}^{3}-3 / \mu_{m_{2}}^{2}\right)}{3 M^{2}\left(R_{2}^{b}-P_{2}^{*}\right)}\right] \\
=\frac{M\left(R_{2}^{b}+C_{2}\right)}{\left(R_{2}^{b}-R_{2}^{a}\right)}+\frac{M S_{m_{2}}}{Q^{*}\left(R_{2}^{b}-R_{2}^{a}\right)}, \\
{\left[\begin{array}{c}
\frac{2 M}{R_{2}^{b}-R_{2}^{a}}+\frac{\left(R_{2}^{b}-R_{2}^{a}\right) h_{m_{21}} Q^{* 2}\left(1-1 / \mu_{m_{2}}\right)}{M \mu_{m_{2}}\left(R_{2}^{b}-P_{2}^{*}\right)^{2}} \\
\left.+\frac{h_{m_{22}} Q^{* 3}\left(R_{2}^{b}-R_{2}^{a}\right)^{2}\left(1+1 / 6 \mu_{m_{2}}^{3}-3 / \mu_{m_{2}}^{2}\right)}{M^{2}\left(R_{2}^{b}-P_{2}^{*}\right)}\right]
\end{array}\right.}
\end{gathered}
$$

$>0$.

Proof. Using the value of optimum lot size $Q^{*}$ from the follower manufacturer 1 , the profit equation of manufacturer 2 becomes

$$
\operatorname{AP}_{m_{2}}\left(P_{2}\right)=\left(P_{2}-C_{2}\right) D_{m_{2}}-\frac{S_{m_{2}} D_{m_{2}}}{Q^{*}}
$$

$$
\begin{aligned}
& -\frac{h_{m_{21}} Q^{* 2}}{2 D_{m_{2}} \mu_{m_{2}}}\left(1-\frac{1}{\mu_{m_{2}}}\right) \\
& -\frac{h_{m_{22}} Q^{* 3}}{6 D_{m_{2}}^{2}}\left(1+\frac{1}{6 \mu_{m_{2}}^{3}}-\frac{3}{\mu_{m_{2}}^{2}}\right) .
\end{aligned}
$$

From the necessary condition of optimization, it can be obtained as

$$
\begin{aligned}
& \frac{d \mathrm{AP}_{m_{2}}}{d P_{2}}=0 \\
& \text { i.e, }\left[\frac{2 M P_{2}^{*}}{R_{2}^{b}-R_{2}^{a}}+\frac{\left(R_{2}^{b}-R_{2}^{a}\right) h_{m_{21}} Q^{* 2}\left(1-1 / \mu_{m_{2}}\right)}{2 M \mu_{m_{2}}\left(R_{2}^{b}-P_{2}^{*}\right)^{2}}\right. \\
& \left.+\frac{h_{m_{22}} Q^{* 3}\left(R_{2}^{b}-R_{2}^{a}\right)^{2}\left(1+1 / 6 \mu_{m_{2}}^{3}-3 / \mu_{m_{2}}^{2}\right)}{3 M^{2}\left(R_{2}^{b}-P_{2}^{*}\right)}\right] \\
& =\frac{M\left(R_{2}^{b}+C_{2}\right)}{\left(R_{2}^{b}-R_{2}^{a}\right)}+\frac{M S_{m_{2}}}{Q^{*}\left(R_{2}^{b}-R_{2}^{a}\right)} .
\end{aligned}
$$

The optimum selling-price $P_{2}^{*}$ of product 2 satisfied the above equation. From the sufficient condition, one can obtain

$$
\begin{aligned}
& \frac{d^{2} \mathrm{AP}_{m_{2}}}{d P^{2}}=\left[-\frac{2 M}{R_{2}^{b}-R_{2}^{a}}\right. \\
& -\frac{\left(R_{2}^{b}-R_{2}^{a}\right) h_{m_{21}} Q^{* 2}\left(1-1 / \mu_{m_{2}}\right)}{M \mu_{m_{2}}\left(R_{2}^{b}-P_{2}^{*}\right)^{2}} \\
& \left.-\frac{h_{m_{22}} Q^{* 3}\left(R_{2}^{b}-R_{2}^{a}\right)^{2}\left(1+1 / 6 \mu_{m_{2}}^{3}-3 / \mu_{m_{2}}^{2}\right)}{M^{2}\left(R_{2}^{b}-P_{2}^{*}\right)}\right] \\
& <0 .
\end{aligned}
$$

Thus, manufacturer 2 has also global maximum profit.

Theorem 3. Using the optimum lot size $Q^{*}$, the global maximum profit is obtained for the common retailer at

$$
P_{r}^{*}=\frac{1}{2}\left[\frac{A}{Q^{*}}+\frac{2+R_{2}^{a}+R_{2}^{b}}{2}+\left(P_{1}^{*}+P_{2}^{*}\right)\right] .
$$

Proof. The profit equation of the common retailer can be written after substituting the value of $Q^{*}$ as

$$
\begin{aligned}
\operatorname{AP}_{r}\left(P_{r}\right)= & -\frac{A M\left(2+R_{2}^{a}+R_{2}^{b}-2 P_{r}\right)}{2 Q^{*}}+\frac{h_{r} Q^{*}}{2} \\
& +\frac{\left(P_{r}-P_{1}-P_{2}\right)\left(2+R_{2}^{a}+R_{2}^{b}-2 P_{r}\right)}{2} .
\end{aligned}
$$


The optimum $P_{r}$ is obtained by taking derivative of $\operatorname{AP}_{r}\left(P_{r}\right)$ with respect to $P_{r}$ and equating to zero, as follows:

$$
\begin{aligned}
& P_{r}^{*}=\frac{1}{2}\left[\frac{A}{Q^{*}}+\frac{2+R_{2}^{a}+R_{2}^{b}}{2}+\left(P_{1}^{*}+P_{2}^{*}\right)\right] \\
& \text { as, } \frac{d^{2} \operatorname{AP}_{r}\left(P_{r}\right)}{d P_{r}^{2}}=-2 M<0 .
\end{aligned}
$$

Therefore, for each case, the model obtains the global maximum solution analytically.

Case 2 (cooperation between leaders (manufacturer 2 and common retailer) and follower (manufacturer 1)). For this case, the leaders think about their joint profit, not the individual profit. Thus, the cooperation strategy can be considered within the leaders and follower. Due to the leader-follower policy, the model is solved by Stackelberg game approach. As the follower is the same as Case 1, thus we can use the same value of lot size $Q^{*}$ and selling-price $P_{1}^{*}$ of product 1 . Thus, we formulate a theorem as follows.

Theorem 4. $P_{2}^{*}$ and $P_{r}^{*}$ are the global optimum selling-price for product 2 and bundle product, respectively, of manufacturer 2 and common retailer if the following are satisfied:

$$
\begin{aligned}
& {\left[\frac{2 M P_{2}^{*}}{R_{2}^{b}-R_{2}^{a}}+\frac{\left(R_{2}^{b}-R_{2}^{a}\right) h_{m_{21}} Q^{* 2}\left(1-1 / \mu_{m_{2}}\right)}{2 M \mu_{m_{2}}\left(R_{2}^{b}-P_{2}^{*}\right)^{2}}\right.} \\
& \left.+\frac{h_{m_{22}} Q^{* 3}\left(R_{2}^{b}-R_{2}^{a}\right)^{2}\left(1+1 / 6 \mu_{m_{2}}^{3}-3 / \mu_{m_{2}}^{2}\right)}{3 M^{2}\left(R_{2}^{b}-P_{2}^{*}\right)}\right] \\
& +\frac{M\left(2-2 P_{r}+R_{2}^{b}+R_{2}^{a}\right)}{2}=\frac{M\left(R_{2}^{b}+C_{2}\right)}{\left(R_{2}^{b}-R_{2}^{a}\right)} \\
& +\frac{M S_{m_{2}}}{Q^{*}\left(R_{2}^{b}-R_{2}^{a}\right)} \\
& P_{r}=\frac{1}{Q^{*}}+\frac{\left(P_{1}^{*}+P_{2}^{*}\right)}{2}+\frac{2+R_{2}^{b}+R_{2}^{a}}{4}, \\
& 2 M\left[\frac{2 M}{R_{2}^{b}-R_{2}^{a}}+\frac{\left(R_{2}^{b}-R_{2}^{a}\right) h_{m_{21}} Q^{* 2}\left(1-1 / \mu_{m_{2}}\right)}{M \mu_{m_{2}}\left(R_{2}^{b}-P_{2}^{*}\right)^{2}}\right. \\
& \left.+\frac{h_{m_{22}} Q^{* 3}\left(R_{2}^{b}-R_{2}^{a}\right)^{2}\left(1+1 / 6 \mu_{m_{2}}^{3}-3 / \mu_{m_{2}}^{2}\right)}{M^{2}\left(R_{2}^{b}-P_{2}^{*}\right)}\right] \\
& -M^{2}>0 \text {. }
\end{aligned}
$$

Proof. The joint profit of the leaders is

$$
\begin{aligned}
& \operatorname{AP}_{m_{2 r}}\left(P_{2}, P_{r}, Q\right) \\
& \quad=\left(P_{2}-C_{2}\right) D_{m_{2}}-\frac{S_{m_{2}} D_{m_{2}}}{Q^{*}}
\end{aligned}
$$

$$
\begin{aligned}
& -\frac{h_{m_{21}} Q^{* 2}}{2 D_{m_{2}} \mu_{m_{2}}}\left(1-\frac{1}{\mu_{m_{2}}}\right) \\
& -\frac{h_{m_{22}} Q^{* 3}}{6 D_{m_{2}}^{2}}\left(1+\frac{1}{6 \mu_{m_{2}}^{3}}-\frac{3}{\mu_{m_{2}}^{2}}\right) \\
& +\left(P_{r}-P_{1}-P_{2}\right) \frac{M\left(2-2 P_{r}+R_{2}^{b}+R_{2}^{a}\right)}{2} \\
& -\frac{A M\left(2-2 P_{r}+R_{2}^{b}+R_{2}^{a}\right)}{Q}-\frac{h_{r} Q}{2} .
\end{aligned}
$$

To optimize the joint profit, taking differentiation two times with respect to $P_{r}^{*}$, one can obtain

$$
\begin{aligned}
\frac{\partial \mathrm{AP}_{m_{2 r}}}{\partial P_{r}}= & \frac{M\left(2-2 P_{r}+R_{2}^{b}+R_{2}^{a}\right)}{2} \\
& -M\left(P_{r}-P_{1}-P_{2}\right)+\frac{2 A M}{Q^{*}}, \\
\frac{\partial^{2} \mathrm{AP}_{m_{2 r}}}{\partial P_{r}^{2}}= & -2 M<0 .
\end{aligned}
$$

Now, differentiate $\partial \mathrm{AP}_{m_{2 r}} / \partial P_{r}$ with respect to $P_{2}$; it is found that

$$
\frac{\partial^{2} \mathrm{AP}_{m_{2 r}}}{\partial P_{2} \partial P_{r}}=M .
$$

Now, putting the value of demand, one can find

$$
\begin{aligned}
& \mathrm{AP}_{m_{2 r}}\left(P_{2}, P_{r}\right)=\left(P_{2}-C_{2}\right) M\left(\frac{R_{2}^{b}-P_{2}}{R_{2}^{b}-R_{2}^{a}}\right) \\
& -\frac{S_{m_{2}} M\left(\left(R_{2}^{b}-P_{2}\right) /\left(R_{2}^{b}-R_{2}^{a}\right)\right)}{Q} \\
& -\frac{h_{m_{21}} Q^{* 2}}{2 M\left(\left(R_{2}^{b}-P_{2}\right) /\left(R_{2}^{b}-R_{2}^{a}\right)\right) \mu_{m_{2}}}\left(1-\frac{1}{\mu_{m_{2}}}\right) \\
& -\frac{h_{m_{22}} Q^{* 3}}{6 M^{3}\left(\left(R_{2}^{b}-P_{2}\right) /\left(R_{2}^{b}-R_{2}^{a}\right)\right)^{2}}\left(1+\frac{1}{6 \mu_{m_{2}}^{3}}\right. \\
& \left.-\frac{3}{\mu_{m_{2}}^{2}}\right)+\left(P_{r}-P_{1}-P_{2}\right) \frac{M\left(2-2 P_{r}+R_{2}^{b}+R_{2}^{a}\right)}{2} \\
& -\frac{A M\left(2-2 P_{r}+R_{2}^{b}+R_{2}^{a}\right)}{Q}-\frac{h_{r} Q}{2} \\
& \frac{d \mathrm{AP} m_{m_{2 r}}}{d P_{2}}=0
\end{aligned}
$$




$$
\begin{aligned}
\text { i.e, } & {\left[\frac{2 M P_{2}^{*}}{R_{2}^{b}-R_{2}^{a}}+\frac{\left(R_{2}^{b}-R_{2}^{a}\right) h_{m_{21}} Q^{* 2}\left(1-1 / \mu_{m_{2}}\right)}{2 M \mu_{m_{2}}\left(R_{2}^{b}-P_{2}^{*}\right)^{2}}\right.} \\
+ & \left.\frac{h_{m_{22}} Q^{* 3}\left(R_{2}^{b}-R_{2}^{a}\right)^{2}\left(1+1 / 6 \mu_{m_{2}}^{3}-3 / \mu_{m_{2}}^{2}\right)}{3 M^{2}\left(R_{2}^{b}-P_{2}^{*}\right)}\right] \\
+ & \frac{M\left(2-2 P_{r}+R_{2}^{b}+R_{2}^{a}\right)}{2}=\frac{M\left(R_{2}^{b}+C_{2}\right)}{\left(R_{2}^{b}-R_{2}^{a}\right)} \\
+ & \frac{M S_{m_{2}}}{Q^{*}\left(R_{2}^{b}-R_{2}^{a}\right)} .
\end{aligned}
$$

The optimum selling-price $P_{2}^{*}$ of product 2 satisfied the above equation.

From the sufficient condition, one can obtain

$$
\begin{aligned}
& \frac{d^{2} \mathrm{AP}_{m_{2 r}}}{d P_{2}^{2}}=-\left[\frac{2 M}{R_{2}^{b}-R_{2}^{a}}\right. \\
& +\frac{\left(R_{2}^{b}-R_{2}^{a}\right) h_{m_{21}} Q^{* 2}\left(1-1 / \mu_{m_{2}}\right)}{M \mu_{m_{2}}\left(R_{2}^{b}-P_{2}^{*}\right)^{3}} \\
& \left.+\frac{h_{m_{22}} Q^{* 3}\left(R_{2}^{b}-R_{2}^{a}\right)^{2}\left(1+1 / 6 \mu_{m_{2}}^{3}-3 / \mu_{m_{2}}^{2}\right)}{M^{2}\left(R_{2}^{b}-P_{2}^{*}\right)^{4}}\right] \\
& <0 \\
& \frac{\partial^{2} \mathrm{AP}}{\partial P_{2 r}} \frac{\partial^{2} \mathrm{AP}{m_{2 r}}_{2}-\left(\frac{\partial^{2} \mathrm{AP}}{\partial P_{m_{2 r}}}\right)^{2}=2 M\left[\frac{2 M}{R_{2}^{b}-R_{2}^{a}}\right.}{+\frac{\left(R_{2}^{b}-R_{2}^{a}\right) h_{m_{21}} Q^{* 2}\left(1-1 / \mu_{m_{2}}\right)}{M \mu_{m_{2}}\left(R_{2}^{b}-P_{2}^{*}\right)^{2}}} \\
& +M^{2}>0 . \\
& \left.+\frac{h_{m_{22}} Q^{* 3}\left(R_{2}^{b}-R_{2}^{a}\right)^{2}\left(1+1 / 6 \mu_{m_{2}}^{3}-3 / \mu_{m_{2}}^{2}\right)}{M^{2}\left(R_{2}^{b}-P_{2}^{*}\right)}\right]
\end{aligned}
$$

Thus, it satisfies the necessary and sufficient condition for the global optimum solution. Hence, both the selling-prices are the global optimal solutions. This completes the proof.

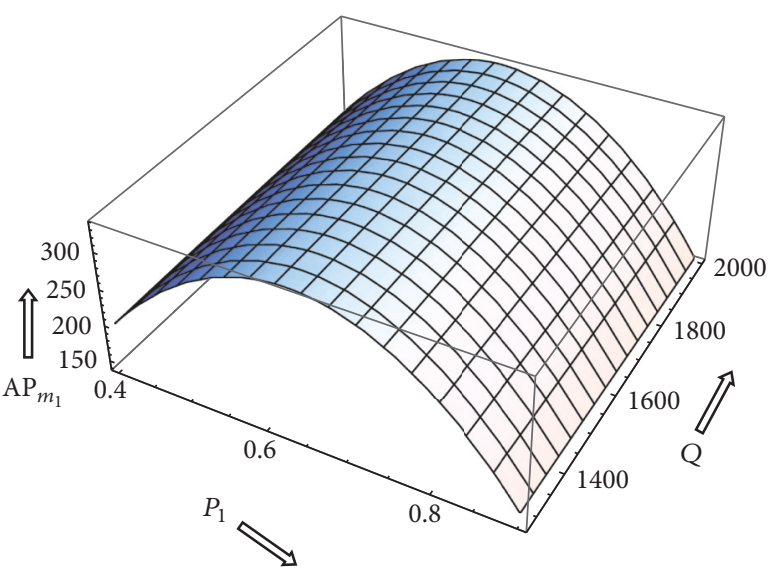

FIGURE 4: Profit of manufacturer 1 versus selling-price of product 1 and lot size for Case 1 .

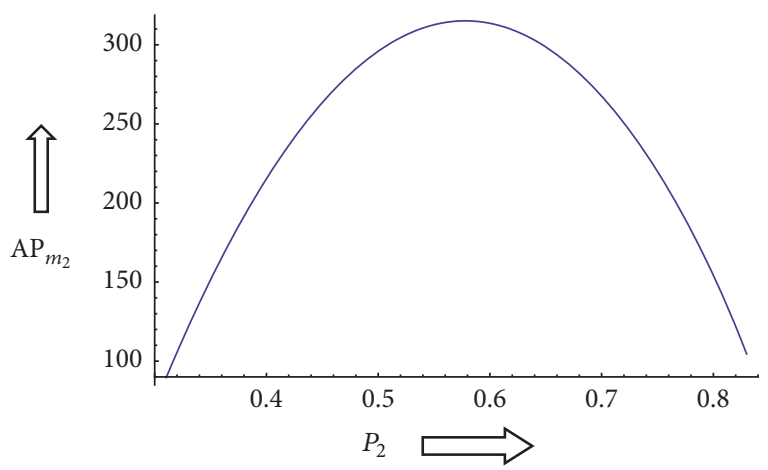

FIGURE 5: Profit of manufacturer 2 versus selling-price of product 2 for Case 1.

\section{Numerical Example}

Input data for the numerical is given in Table 2 and the optimum results are shown in Table 3 . Figures 4, 5, and 6 depict graphical representations for Case 1 and Figures 4 and 7 are graphical representation of Case 2.

\section{Sensitivity Analysis}

The sensitivity analysis of key parameters is considered and major findings can be concluded from the sensitivity analysis, Tables 4 and 5.

5.1. Sensitivity Analysis and Managerial Insights from the Numerical Experiment in Case 1

(1) The market size is the most sensitive parameter among all parameters for all players. From numerical experiments, it is found that, for $50 \%$ increasing values of market size, the total profit for each player increases more than 50\%. Among all players, the market size of manufacturer 2 is most sensitive. Industry managers should be very careful about this most sensitive parameter as if they can increase sales 
TABLE 2: Input values for parameters.

\begin{tabular}{lccccccc}
\hline Player & Market size & Setup cost & $\begin{array}{c}\text { Constant } \\
\text { holding cost } \\
\text { S/unit/year }\end{array}$ & $\begin{array}{c}\text { Variable holding } \\
\text { cost } \\
\text { units/year }\end{array}$ & $\begin{array}{c}\text { Purchasing cost } \\
\text { \$/unit }\end{array}$ & $\begin{array}{c}\text { Scaling } \\
\text { parameter }\end{array}$ & $\begin{array}{c}\text { Reservation } \\
\text { price interval }\end{array}$ \\
\hline Manufacturer 1 & $M=2500$ & $S_{m_{1}}=20$ & $h_{m_{11}}=0.015$ & $h_{m_{12}}=0.005$ & $C_{1}=0.250$ & $\mu_{m_{1}}=5$ & {$[0,1]$} \\
Manufacturer 2 & $M=2500$ & $S_{m_{2}}=20$ & $h_{m_{21}}=0.015$ & $h_{m_{22}}=0.005$ & $C_{2}=0.250$ & $\mu_{m_{2}}=5$ & {$[0.1,0.9]$} \\
Retailer & $M=2500$ & $A=1$ & $h_{r}=0.001$ & - & - & - & {$[0.1,0.9]$} \\
\hline
\end{tabular}

- indicates that the parameter is not available for this case.

TABLE 3: Optimum results of numerical example.

\begin{tabular}{|c|c|c|c|c|c|c|c|c|c|}
\hline Case & $\begin{array}{c}Q^{*} \\
\text { Units }\end{array}$ & $\begin{array}{c}P_{1}^{*} \\
\text { \$/unit }\end{array}$ & $\begin{array}{c}P_{2}^{*} \\
\$ / \text { unit }\end{array}$ & $\begin{array}{c}P_{r}^{*} \\
\text { \$/unit }\end{array}$ & $\begin{array}{l}\mathrm{AP}_{m_{1}}^{*} \\
\$ / \text { year }\end{array}$ & $\begin{array}{l}\mathrm{AP}_{m_{2}}^{*} \\
\$ / \text { year }\end{array}$ & $\begin{array}{c}\mathrm{AP}_{r}^{*} \\
\text { \$/year }\end{array}$ & $\begin{array}{l}\mathrm{AP}_{m_{2 r}}^{*} \\
\$ / \text { year }\end{array}$ & $\begin{array}{l}\mathrm{AP}_{\mathrm{SCM}}^{*} \\
\$ / \text { year }\end{array}$ \\
\hline 1 & 1932.66 & 0.63 & 0.58 & 1.35 & 337.09 & 315.18 & 53.03 & - & 705.30 \\
\hline 2 & 1932.66 & 0.63 & 0.51 & 1.32 & 337.09 & - & - & 381.53 & 718.62 \\
\hline
\end{tabular}

- indicates that the average profit is not available for this case.

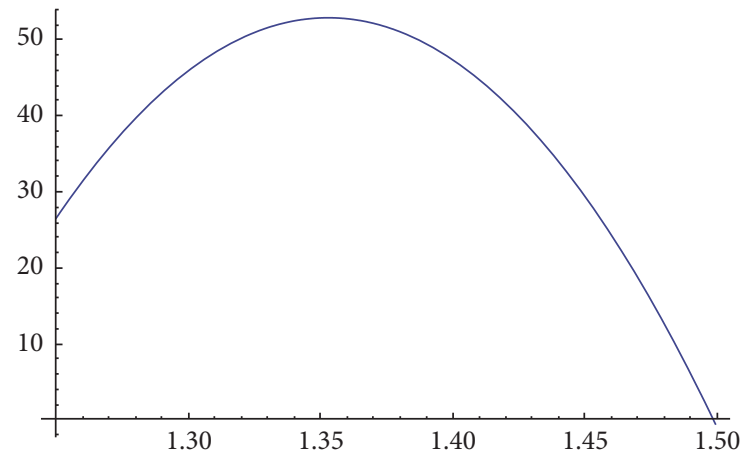

Figure 6: Profit of common retailer versus selling-price of bundle product for Case 1 .

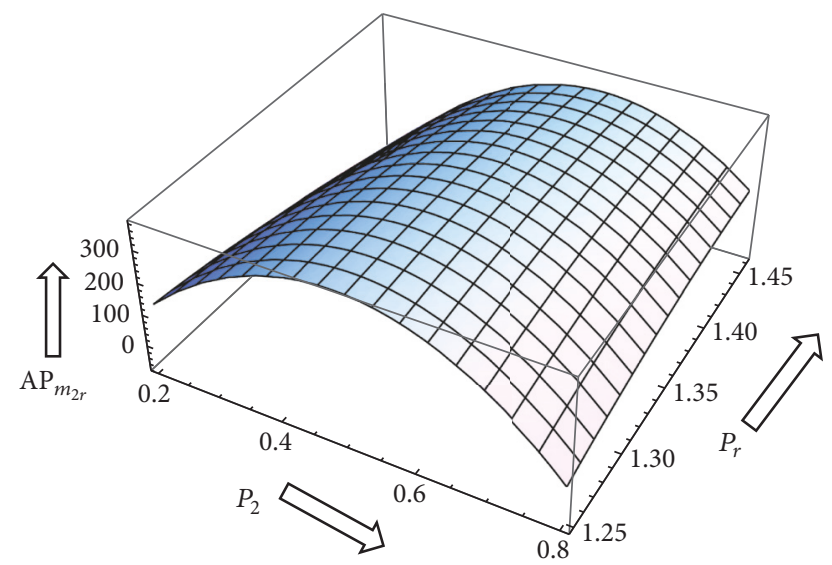

FIGURE 7: Profit of manufacturer 2 and common retailer versus selling-price of product 2 and bundle product for Case 2 . by using any strategy or policy, the profit curve of each player can rise significantly.

(2) For the setup cost, the cost is most sensitive for manufacturer 2 comparing to manufacturer 1 . For manufacturer 2, the positive and negative change in total profit are almost same, whereas, for manufacturer 1 , the positive change is more than the negative change in total profit. Positive and negative changes in the total profit are the same for the ordering cost of the common retailer.

(3) Among all players of the supply chain, the holding cost for the common retailer is most sensitive parameter. Within those manufacturers, manufacturer 1's profit is most sensitive than manufacturer 1's profit for the holding cost. For the time-dependent part of holding cost, it is found that this holding cost is very less sensitive comparing to others, but not negligible. The positive and negative changes in the time-dependent holding costs for both manufacturers are the same, which indicates that, for both cases, they are in equilibrium position.

(4) The purchasing costs for both manufacturers are second sensitive parameters among all other parameters. For both manufacturers, the positive change in the total profit is more than the negative change in the total profit in the case of purchasing cost.

(5) The changes in the total profit are very less for both the scaling parameters for the variable production rate; still it is most useful for the model, which is found by the numerical experiments. 
TABLE 4: Sensitivity analysis for Case 1.

\begin{tabular}{|c|c|c|c|c|}
\hline & $\begin{array}{c}\text { Parameter } \\
\text { Change (in \%) }\end{array}$ & $\begin{array}{l}\mathrm{AP}_{m_{1}} \\
\text { (in \%) }\end{array}$ & $\begin{array}{l}\mathrm{AP}_{m_{2}} \\
\text { (in \%) }\end{array}$ & $\begin{array}{c}\mathrm{AP}_{r} \\
\text { (in \%) }\end{array}$ \\
\hline \multirow{4}{*}{$M$} & $-50 \%$ & -51.26 & -52.11 & -50.91 \\
\hline & $-25 \%$ & -25.68 & -25.82 & -25.46 \\
\hline & $+25 \%$ & +25.74 & +25.64 & +25.46 \\
\hline & $+50 \%$ & +51.52 & +51.18 & +50.91 \\
\hline \multirow{4}{*}{$S_{m_{1}}$} & $-50 \%$ & +1.59 & & \\
\hline & $-25 \%$ & +0.75 & & \\
\hline & $+25 \%$ & -0.69 & & \\
\hline & $+50 \%$ & -1.33 & & \\
\hline \multirow{4}{*}{$h_{m_{11}}$} & $-50 \%$ & +0.88 & & \\
\hline & $-25 \%$ & +0.39 & & \\
\hline & $+25 \%$ & -0.33 & & \\
\hline & $+50 \%$ & -0.62 & & \\
\hline \multirow{4}{*}{$h_{m_{12}}$} & $-50 \%$ & +0.0005 & & \\
\hline & $-25 \%$ & +0.0002 & & \\
\hline & $+25 \%$ & -0.0002 & & \\
\hline & $+50 \%$ & -0.0005 & & \\
\hline \multirow{4}{*}{$C_{1}$} & $-50 \%$ & +37.39 & & \\
\hline & $-25 \%$ & +17.98 & & \\
\hline & $+25 \%$ & -16.55 & & \\
\hline & $+50 \%$ & -31.67 & & \\
\hline \multirow{4}{*}{$\mu_{m_{1}}$} & $-50 \%$ & -0.71 & & \\
\hline & $-25 \%$ & -0.32 & & \\
\hline & $+25 \%$ & +0.23 & & \\
\hline & $+50 \%$ & +0.40 & & \\
\hline \multirow{4}{*}{$S_{m_{2}}$} & $-50 \%$ & & +1.66 & \\
\hline & $-25 \%$ & & +0.83 & \\
\hline & $+25 \%$ & & -0.82 & \\
\hline & $+50 \%$ & & -1.65 & \\
\hline \multirow{4}{*}{$h_{m_{21}}$} & $-50 \%$ & & +0.71 & \\
\hline & $-25 \%$ & & +0.35 & \\
\hline & $+25 \%$ & & -0.35 & \\
\hline & $+50 \%$ & & -0.70 & \\
\hline \multirow{4}{*}{$h_{m_{22}}$} & $-50 \%$ & & +0.0004 & \\
\hline & $-25 \%$ & & +0.0002 & \\
\hline & $+25 \%$ & & -0.0002 & \\
\hline & $+50 \%$ & & -0.0004 & \\
\hline \multirow{4}{*}{$C_{2}$} & $-50 \%$ & & +43.74 & \\
\hline & $-25 \%$ & & +20.91 & \\
\hline & $+25 \%$ & & -19.00 & \\
\hline & $+50 \%$ & & -36.10 & \\
\hline \multirow{4}{*}{$\mu_{m_{2}}$} & $-50 \%$ & & -0.70 & \\
\hline & $-25 \%$ & & -0.31 & \\
\hline & $+25 \%$ & & +0.23 & \\
\hline & $+50 \%$ & & +0.39 & \\
\hline \multirow{4}{*}{ A } & $-50 \%$ & & & +0.18 \\
\hline & $-25 \%$ & & & +0.09 \\
\hline & $+25 \%$ & & & -0.09 \\
\hline & $+50 \%$ & & & -0.18 \\
\hline
\end{tabular}

TABle 4: Continued.

\begin{tabular}{|c|c|c|c|c|}
\hline & $\begin{array}{c}\text { Parameter } \\
\text { Change (in \%) }\end{array}$ & $\begin{array}{l}\mathrm{AP}_{m_{1}} \\
(\text { in } \%)\end{array}$ & $\begin{array}{l}\mathrm{AP}_{m_{2}} \\
(\text { in } \%)\end{array}$ & $\begin{array}{c}\mathrm{AP}_{r} \\
\text { (in \%) }\end{array}$ \\
\hline \multirow{4}{*}{$h_{r}$} & $-50 \%$ & & & +0.91 \\
\hline & $-25 \%$ & & & +0.45 \\
\hline & $+25 \%$ & & & -0.45 \\
\hline & $+50 \%$ & & & -0.91 \\
\hline
\end{tabular}

\section{Conclusions}

This study derived a two-echelon supply chain model with two manufacturers and one common retailer. Two manufacturers produced two different types of complementary products and sold them to the common retailer. The retailer made those complementary products in bundles and sold the bundles to customers. Based on the order quantities by the retailer, at least one manufacturer agreed with the retailer and another manufacturer had to agree with the same order quantities. Thus, the study considered Stackelberg game policy to solve the model. This study used a demanddependent production rate such that shortages did not appear and time-dependent holding cost is used by the study to obtain more profit than existing literature (Sarkar and Lee [2]). The numerical study proved that this model obtained more profit than Sarkar and Lee's [2] model in all respect even though the optimum selling-price for product 1 is the same. If the values of $h_{12}$ and $h_{22}$ are zeros, then the profit will be more, but that is not more realistic. The semiclosed optimal solutions are obtained analytically. There were four theorems to obtain the global optimality analytically. The numerical study proved also the global optimum results. From the numerical study of two cases, the cooperation case gave more profit than the noncooperation case. Thus players should go for cooperation strategy forever for more profit always. Any industry can use the cooperative policy with other industries for continuous profit for complementary products. Further extension of this model is possible to consider uncertainty within the model. A fruitful research direction is possible by considering service level for the retailer (see for reference Shin et al. [15]). For both manufacturers, the setup cost can be reduced by some investments or quality of products can be improved. During production of complementary products, due to long-run process or machine breakdown, defective items may appear and the rate of defective items can be random (Sarkar [16]). In this model, transportation cost for the raw material and final products is not considered. By considering the transportation and carbon emission cost, the model can be reconsidered in a fruitful direction with equal lot size (Sarkar [17]) and with unequal lot size (Sarkar et al. [18]). To facilitate customers with delay-in-payments, the retailer can offer customers to increase more sales (Sarkar [19]). Considering the variable production rate, the model can be considered within the certain limit of production rate, that is, within the range of minimum production rate and maximum production rate (see for reference Sana et al. [20] and Glock [21]). 
TABLE 5: Sensitivity analysis for Case 2.

\begin{tabular}{|c|c|c|c|}
\hline & $\begin{array}{c}\text { Parameter } \\
\text { Change (in \%) }\end{array}$ & $\begin{array}{l}\mathrm{AP}_{m_{1}} \\
\text { (in \%) }\end{array}$ & $\begin{array}{l}\mathrm{AP}_{m_{2 r}} \\
\text { (in \%) }\end{array}$ \\
\hline \multirow{4}{*}{$M$} & $-50 \%$ & -51.26 & -51.55 \\
\hline & $-25 \%$ & -25.68 & -25.62 \\
\hline & $+25 \%$ & +25.74 & +25.49 \\
\hline & $+50 \%$ & +51.52 & +50.92 \\
\hline \multirow{4}{*}{$S_{m_{1}}$} & $-50 \%$ & +1.59 & \\
\hline & $-25 \%$ & +0.75 & \\
\hline & $+25 \%$ & -0.69 & \\
\hline & $+50 \%$ & -1.33 & \\
\hline \multirow{4}{*}{$h_{m_{11}}$} & $-50 \%$ & +0.88 & \\
\hline & $-25 \%$ & +0.39 & \\
\hline & $+25 \%$ & -0.33 & \\
\hline & $+50 \%$ & -0.62 & \\
\hline \multirow{4}{*}{$h_{m_{12}}$} & $-50 \%$ & +0.0005 & \\
\hline & $-25 \%$ & +0.0002 & \\
\hline & $+25 \%$ & -0.0002 & \\
\hline & $+50 \%$ & -0.0005 & \\
\hline \multirow{4}{*}{$C_{1}$} & $-50 \%$ & +37.39 & \\
\hline & $-25 \%$ & +17.98 & \\
\hline & $+25 \%$ & -16.55 & \\
\hline & $+50 \%$ & -31.67 & \\
\hline \multirow{4}{*}{$\mu_{m_{1}}$} & $-50 \%$ & -0.71 & \\
\hline & $-25 \%$ & -0.32 & \\
\hline & $+25 \%$ & +0.23 & \\
\hline & $+50 \%$ & +0.40 & \\
\hline \multirow{4}{*}{$S_{m_{2}}$} & $-50 \%$ & & +1.68 \\
\hline & $-25 \%$ & & +0.84 \\
\hline & $+25 \%$ & & -0.83 \\
\hline & $+50 \%$ & & -1.67 \\
\hline \multirow{4}{*}{$h_{m_{21}}$} & $-50 \%$ & & +0.48 \\
\hline & $-25 \%$ & & +0.24 \\
\hline & $+25 \%$ & & -0.24 \\
\hline & $+50 \%$ & & -0.48 \\
\hline \multirow{4}{*}{$h_{m_{22}}$} & $-50 \%$ & & +0.0002 \\
\hline & $-25 \%$ & & +0.0001 \\
\hline & $+25 \%$ & & -0.0001 \\
\hline & $+50 \%$ & & -0.0002 \\
\hline \multirow{4}{*}{$C_{2}$} & $-50 \%$ & & +44.37 \\
\hline & $-25 \%$ & & +21.19 \\
\hline & $+25 \%$ & & -19.21 \\
\hline & $+50 \%$ & & -36.45 \\
\hline \multirow{4}{*}{$\mu_{m_{2}}$} & $-50 \%$ & & -0.48 \\
\hline & $-25 \%$ & & -0.21 \\
\hline & $+25 \%$ & & +0.15 \\
\hline & $+50 \%$ & & +0.26 \\
\hline \multirow{4}{*}{$A$} & $-50 \%$ & & +0.03 \\
\hline & $-25 \%$ & & +0.02 \\
\hline & $+25 \%$ & & -0.02 \\
\hline & $+50 \%$ & & -0.03 \\
\hline
\end{tabular}

TABLE 5: Continued.

\begin{tabular}{cccc}
\hline & $\begin{array}{c}\text { Parameter } \\
\text { Change (in \%) }\end{array}$ & $\begin{array}{c}\mathrm{AP}_{m_{1}} \\
\text { (in \%) }\end{array}$ & $\begin{array}{c}\mathrm{AP}_{m_{2 r}} \\
\text { (in \%) }\end{array}$ \\
\hline & $-50 \%$ & & +0.13 \\
$h_{r}$ & $-25 \%$ & & +0.06 \\
& $+25 \%$ & & -0.06 \\
& $+50 \%$ & & -0.13 \\
\hline
\end{tabular}

\section{Conflicts of Interest}

The authors declare that there are no conflicts of interest regarding the publication of this paper.

\section{Authors' Contributions}

Mitali Sarkar has made the model and finalized the draft. Professor Sarkar has updated the calculations and modeling part and Professor Hur has supervised all process of the paper.

\section{References}

[1] B. Sarkar, "Supply chain coordination with variable backorder, inspections, and discount policy for fixed lifetime products," Mathematical Problems in Engineering, vol. 2016, Article ID 6318737, 14 pages, 2016.

[2] M. Sarkar and Y. H. Lee, "Optimum pricing strategy for complementary products with reservation price in a supply chain model," Journal of Industrial and Management Optimization, vol. 13, no. 2, p. 7, 2017.

[3] L. E. Cárdenas-Barrón and S. S. Sana, "A production-inventory model for a two-echelon supply chain when demand is dependent on sales teams' initiatives," International Journal of Production Economics, vol. 155, pp. 249-258, 2014.

[4] N. M. Modak, S. Panda, and S. S. Sana, "Three-echelon supply chain coordination considering duopolistic retailers with perfect quality products," International Journal of Production Economics, vol. 128, pp. 564-578, 2016.

[5] X. Yue, S. K. Mukhopadhyay, and X. Zhu, "A Bertrand model of pricing of complementary goods under information asymmetry," Journal of Business Research, vol. 59, no. 10-11, pp. 1182-1192, 2006.

[6] S. C. Choi, "Price competition in a channel structure with a common retailer," Marketing Science, vol. 10, no. 4, pp. 271-296, 1991.

[7] J. Gabszewicz, N. Sonnac, and X. Wauthy, "On price competition with complementary goods," Economics Letters, vol. 70, no. 3, pp. 431-437, 2001.

[8] K. F. McCardle, K. Rajaram, and C. S. Tang, "Bundling retail products: models and analysis," European Journal of Operational Research, vol. 177, no. 2, pp. 1197-1217, 2007.

[9] H. K. Alfares and A. M. Ghaithan, "Inventory and pricing model with price-dependent demand, time-varying holding cost, and quantity discounts," Computers \& Industrial Engineering, vol. 94, pp. 170-177, 2016.

[10] B. Sarkar, S. S. Sana, and K. Chaudhuri, "An imperfect production process for time varying demand with inflation and time value of money-an EMQ model," Expert Systems with Applications, vol. 38, no. 11, pp. 13543-13548, 2011. 
[11] S. K. Manna and K. S. Chaudhuri, "An EOQ model with ramp type demand rate, time dependent deterioration rate, unit production cost and shortages," European Journal of Operational Research, vol. 171, no. 2, pp. 557-566, 2006.

[12] B. Sarkar, P. Mandal, and S. Sarkar, "An EMQ model with price and time dependent demand under the effect of reliability and inflation," Applied Mathematics and Computation, vol. 231, pp. 414-421, 2014.

[13] S. K. Mukhopadhyay, X. Yue, and X. Zhu, "A Stackelberg model of pricing of complementary goods under information asymmetry," International Journal of Production Economics, vol. 134, no. 2, pp. 424-433, 2011.

[14] J. Wei, J. Zhao, and Y. Li, "Pricing decisions for complementary products with firms' different market powers," European Journal of Operational Research, vol. 224, no. 3, pp. 507-519, 2013.

[15] D. Shin, R. Guchhait, B. Sarkar, and M. Mittal, "Controllable lead time, service level constraint, and transportation discount in a continuous review inventory model," RAIRO-Operations Research, vol. 50, no. 4-5, pp. 921-934, 2016.

[16] B. Sarkar, "An inventory model with reliability in an imperfect production process," Applied Mathematics and Computation, vol. 218, no. 9, pp. 4881-4891, 2012.

[17] B. Sarkar, "A production-inventory model with probabilistic deterioration in two-echelon supply chain management," Applied Mathematical Modelling, vol. 37, no. 5, pp. 3138-3151, 2013.

[18] B. Sarkar, S. Saren, D. Sinha, and S. Hur, "Effect of unequal lot sizes, variable setup cost, and carbon emission cost in a supply chain model," Mathematical Problems in Engineering, vol. 2015, Article ID 469486, 13 pages, 2015.

[19] B. Sarkar, "An EOQ model with delay in payments and time varying deterioration rate," Mathematical and Computer Modelling, vol. 55, no. 3-4, pp. 367-377, 2012.

[20] S. S. Sana, S. K. Goyal, and K. Chaudhuri, "An imperfect production process in a volume flexible inventory model," International Journal of Production Economics, vol. 105, no. 2, pp. 548-559, 2007.

[21] C. H. Glock, "Batch sizing with controllable production rates in a multi-stage production system," International Journal of Production Research, vol. 49, no. 20, pp. 6017-6039, 2011. 


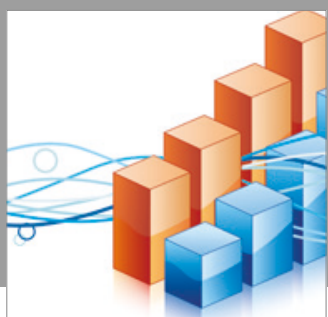

Advances in

Operations Research

vatersals

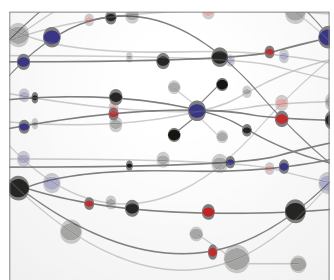

\section{The Scientific} World Journal
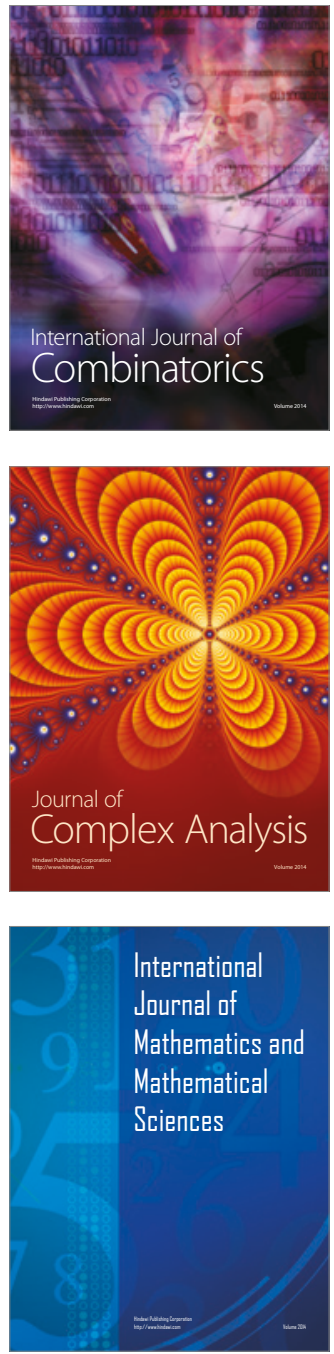
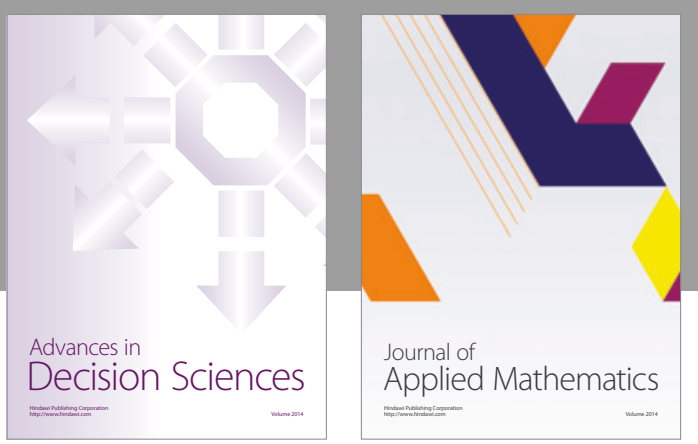

Algebra

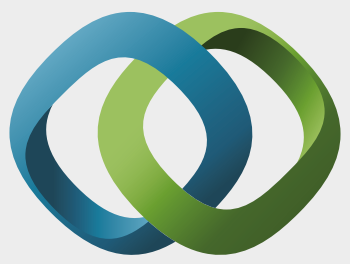

\section{Hindawi}

Submit your manuscripts at

https://www.hindawi.com
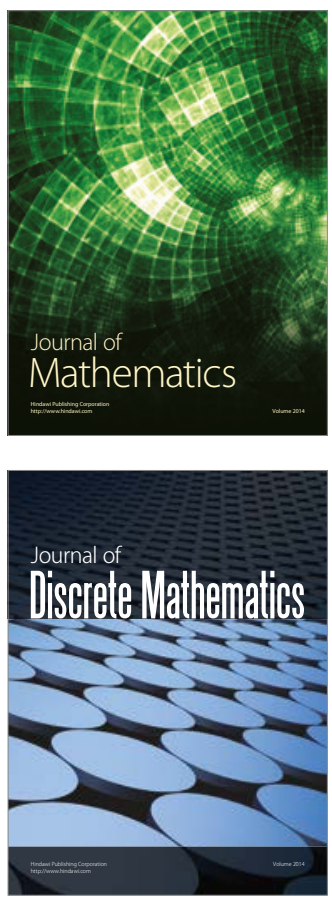

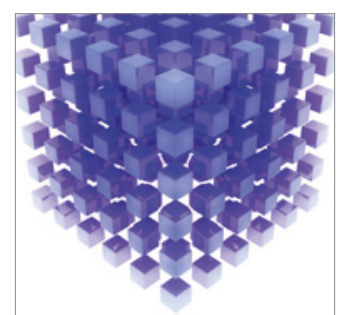

Mathematical Problems in Engineering
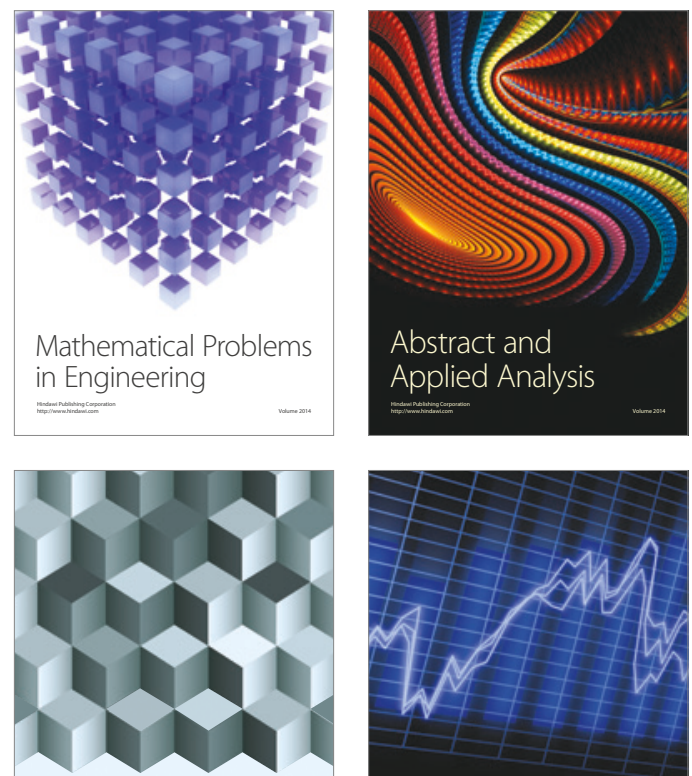

Journal of

Function Spaces

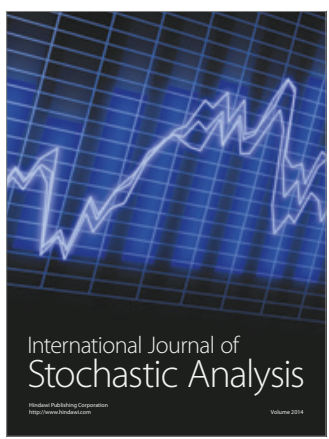

Probability and Statistics
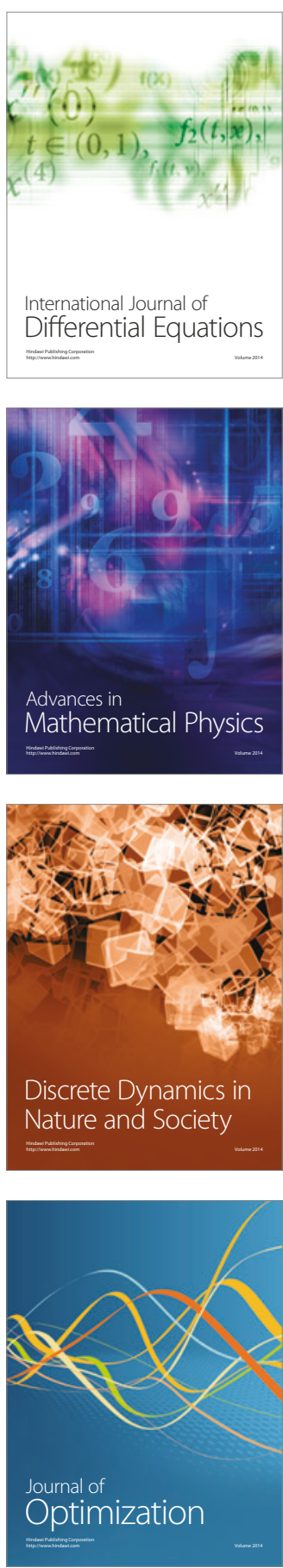